\title{
OPEN Overexpression of OsCM alleviates BLB stress via phytohormonal accumulation and transcriptional modulation of defense-related genes in Oryza sativa
}

Rahmatullah Jan ${ }^{1}$, Muhammad Aaqil Khan ${ }^{1}$, Sajjad Asaf ${ }^{2}$, In-Jung Lee ${ }^{1}$, Jong-Sup Bae ${ }^{3 \bowtie} \&$ Kyung-Min Kim ${ }^{1 \otimes}$

Xanthomonas oryzae is a serious pathogen causing bacterial leaf blight (BLB) disease in rice, markedly reducing its yield. In this study, the rice chorismate mutase (OSCM) gene was overexpressed in a bacterial leaf blight-susceptible rice line to investigate the functional role of $O s C M$ in response to bacterial leaf blight stress. We reported that overexpression of $O s C M$ altered the downstream pathway of aromatic amino acids, mitigating pathogen stress by altering stress-responsive genes and hormonal accumulation. Phenotypic evaluation showed that the lesion length in the transgenic line was significantly lesser than that in the wild-type, suggesting greater resistance in the transgenic line. Further analysis revealed that $\mathrm{OsCM}$ expression induced phenylalanine accumulation and suppressed tyrosine accumulation in response to bacterial leaf blight stress. Furthermore, bacterial leaf blight stress induced genes downstream of the phenylpropanoid pathway in conjunction with $\mathrm{OsCM}$, suggesting that the phenylpropanoid pathway is dependent on $O s C M$ gene expression. We reported high SA and low JA accumulation in response to bacterial leaf blight stress in the transgenic line. This higher SA accumulation suggested that SA induces immune responses by functioning as a promoter of nonexpresser pathogenesis-related genes 1 (NPR1) transcriptional regulation. Xa7 expression was induced with increase in nonexpresser pathogenesis-related genes 1, which is thought to be responsible for $\mathrm{Xa} 7$ expression, which is responsible for mitigating bacterial leaf blight stress.

The yield of rice, a staple food for about $50 \%$ the world's population, is decreased due to biotic and abiotic stresses. Among the biotic stresses, bacterial leaf blight (BLB) is one of the most severe and common rice diseases in most Asian countries; it is caused by Xanthomonas oryzae pv. oryza (Xoo) and results in considerable yield loss each year ${ }^{1}$. Xoo can be more successfully controlled by the development of transgenic resistant varieties of rice, usually through single-gene resistance ${ }^{2}$. Generally, the exposure of plants to pathogens enhances the induction of genes involved in the shikimate pathway and aromatic amino acids (AAAs), such as phenylalanine (Phe), tyrosine (Tyr), and tryptophan (Trp) ${ }^{3}$. Pathogenic attack stimulates the plant cell wall and releases oligogalacturonides, which in turn stimulate the expression of various genes encoding enzymes of the shikimate pathway and AAAs as well as those encoding secondary metabolites derived from Phe and $\mathrm{Tyr}^{4}$. Bacterial pathogens redirect normal host metabolism by delivering a constellation of type III effector proteins to enhance pathogen multiplication and nutrition ${ }^{5,6}$. However, genes associated with AAAs have been significantly modified to cope with bacterial challenges, including cell wall alteration to control the nutrients and water passage from plants to invading bacteria ${ }^{7,8}$. Phe, Tyr, and Trp are the main AAA molecules in plant metabolism which are responsible for synthesis of a number of hormones, such as salicylic acid and auxin, as well as for essential secondary metabolites with many biological functions $s^{9,10}$.

\footnotetext{
${ }^{1}$ Division of Plant Biosciences, School of Applied Biosciences, College of Agriculture and Life Science, Kyungpook National University, 80 Dahak-ro, Buk-gu, Daegu 41566, Republic of Korea. ${ }^{2}$ Natural and Medical Science Research Center, University of Nizwa, 616 Nizwa, Oman. ${ }^{3}$ College of Pharmacy, CMRI, Research Institute of Pharmaceutical Sciences, BK21 Plus KNU Multi-Omics Based Creative Drug Research Team, Kyungpook National University, Daegu 41566, Republic of Korea. ${ }^{\square}$ email: baejs@knu.ac.kr; kkm@knu.ac.kr
} 
Chorismate along with the synthesis of salicylic acid (SA) through isochorismate synthase (ICS) activity ${ }^{11}$ is also the main precursor and initial branch point metabolite in the synthesis of all AAAs and their derivatives. The main route of Phe and Tyr biosynthesis is initiated from the same precursor, chorismite, catalyzed by the chorismate mutase $(C M)$ enzyme to produce prephenate, which is further catalyzed to arogenate by the prephenate aminotransferase (PAT) enzyme. Phe and Tyr are synthesized in two ways. First, prephenate is converted to phenylpyruvate and hydroxyphenylpyruvate via the prephenate dehydratase $(P D T)$ and prephenate dehydrogenase $(P D H)$ enzymes, respectively. Further, phenylpyruvate and hydroxyphenylpyruvate are catalyzed into Phe and Tyr, respectively, through the aromatic amino acid aminotransferase (AAAAT) enzyme. Alternately, prephenate synthesizes arogenate through the prephenate aminotransferase (PAT) enzyme, which is further catalyzed into Phe and Tyr through the arogenate dehydratase (ADT) and arogenate dehydrogenase (TyrA) enzymes, respectively ${ }^{12-14}$. Previous reports support the observation that, in phenylpyruvate containing plants, it also act as a precursor of various secondary metabolites ${ }^{15}$. Phe and Tyr are catabolized to produce anabolic precursors of the most important secondary metabolites through the phenylpropanoid pathway. Phenylalanine ammonia lyase (PAL) is responsible for conversion of Phe into cinnamate; however, Tyr is the directly involved in the synthesis of coumarate in the phenylpropanoid pathway by the tyrosine ammonia lyase enzyme ${ }^{16}$. The gene responsible for the PAL enzyme is regulated during biotic stress and under conditions that increase the need for lignin as a cell wall component ${ }^{17}$. The metabolites of the phenylpropanoid pathway causes toughness to cells which act as pest deterrent and disease resistant ${ }^{18}$. The PAL enzyme is involved in the first step of the phenylpropanoid pathway, through which the synthesis of various secondary metabolites (flavonoid pigments, lignin, antimicrobial phenolics, UV protectants, and cell wall-associated phenolics) take place against biotic, mechanical, and UV stresses, which is a definitive defense reaction to pathogenic attack ${ }^{19}$. Expression of the $C M$ gene induces PAL activity, providing precursors for the biosynthesis of lignin and SA, which change in response to pathogen infection. SA accumulation is essential for systemic acquired resistance (SAR), removing $\mathrm{H}_{2} \mathrm{O}_{2}$ and suppressing the oxidative burst necessary for the HR. A report has shown that SA plays an important role in Xoo resistance in rice and promotes basal as well as hypersensitive responses during Xoo infection in rice $\mathrm{e}^{20}$. The accumulation of SA increases under stress conditions, which translocates NPR1 into the nucleus for SA-dependent transcriptomic changes ${ }^{21}$. NPR1 is hypothesized to be a transcription factor due to its lack of a DNA binding domain and responsibility for Xoo resistance in rice, given that it is responsible for PR gene expression ${ }^{22}$. Furthermore, the SA and JA signaling pathways intersect at various branches because they alter biotic stress antagonistically, which was reported for the first time in tomato ${ }^{23}$. SA inhibits JA accumulation by suppressing JA-responsive genes, which suggests that NPR1 is a key player in the antagonistic cross-talk of SA and JA ${ }^{24}$.

Despite of great importance of chorismate mutase in alteration of shikimate pathway and biosynthesis of AAAs, the role of chorismate mutase in the stress response has been mostly ignored. Although most of the researchers evaluated the function of chorismate mutase associated with the aromatic amino acids and secondary metabolites, but still it is not explored in response to biotic stress. Therefore, the present study focus on role of chorismate mutase in the alteration of the PAL pathway and biotic stress tolerance (BLB) in terms of aromatic amino acid and SA accumulation and transcriptional modulation of defense-related genes in Oryza sativa.

\section{Results}

Cloning and OsCM-overexpressing line development. The complete ORF region of OsCM was successfully cloned into a cloning vector and transferred to $E$. coli cells for multiplication. The isolated plasmid and double digestion with the restriction enzymes Not1 and Asc1, are shown in Fig. 1A,B. The double-digested template was further cloned successfully into an expression vector and transferred into Agrobacterium cells. The plasmid isolated from Agrobacterium was double-digested with BamH1 and Xho1 restriction enzymes (Fig. 1C,D). The OsCM-overexpressing rice line was developed using callus culture; its various developmental stages are described in Fig. 1E-L. The efficiency of transgenic line development was about $18 \%$ using hygromycin as a selection marker. The seeds obtained were used for further analysis.

OsCM is functionally involved in BLB tolerance. To evaluate the differences in morphological characteristics of $O x C M$ and wild-type (WT) rice plants, using the leaf clipping method the plants were inoculated with K3a strain of Xoo. The lesion length upon BLB infection of WT as well as OxCM plants was measured from 1 week after inoculation of the K3a strain, for 5 consecutive weeks. The inoculation of K3a was confirmed through colony counting. The phenotypic evaluation showed that the lesion length increased markedly after each week, indicating that WT plants were highly susceptible to K3a infection (Fig. 2A). However, the lesion length of $O x C M$ plants was much less throughout the five weeks, suggesting that $O x C M$ expressing plant was highly tolerant of K3a.The infection of K3a in WT plants reached the severe stage and finally the leaves died after 5 weeks. The measurement of lesion length showed that the lesions increased from 6 to $138 \mathrm{~mm}$ from the first to the fifth week in WT plants (Fig. 2B). However, in $O x C M$ plants, the lesions increased from 1.1 to $15 \mathrm{~mm}$ from the first to the fifth week. This shows that overexpression of $O s C M$ in rice significantly $(P<0.001)$ enhanced tolerance to BLB.

Pathogen infection enhances OsCM expression and phenylalanine accumulation and suppresses tyrosine. To further investigate the biological function of OsCM in Phe and Tyr accumulation in stressed as well as normal conditions, we infected WT plants and OxCM plants and compared them with uninfected WT and $O x C M$ plants. The OsCM gene expression in the transgenic infected line was significantly different $(P<0.001)$ from that of WT infected plants (Fig. 3A). However, the expression of OsCM in uninfected plants was not significantly higher than that of WT uninfected plants. We also investigated the level of OsCM protein expression in transgenic and WT infected plants. The results showed that OsCM protein was signifi- 

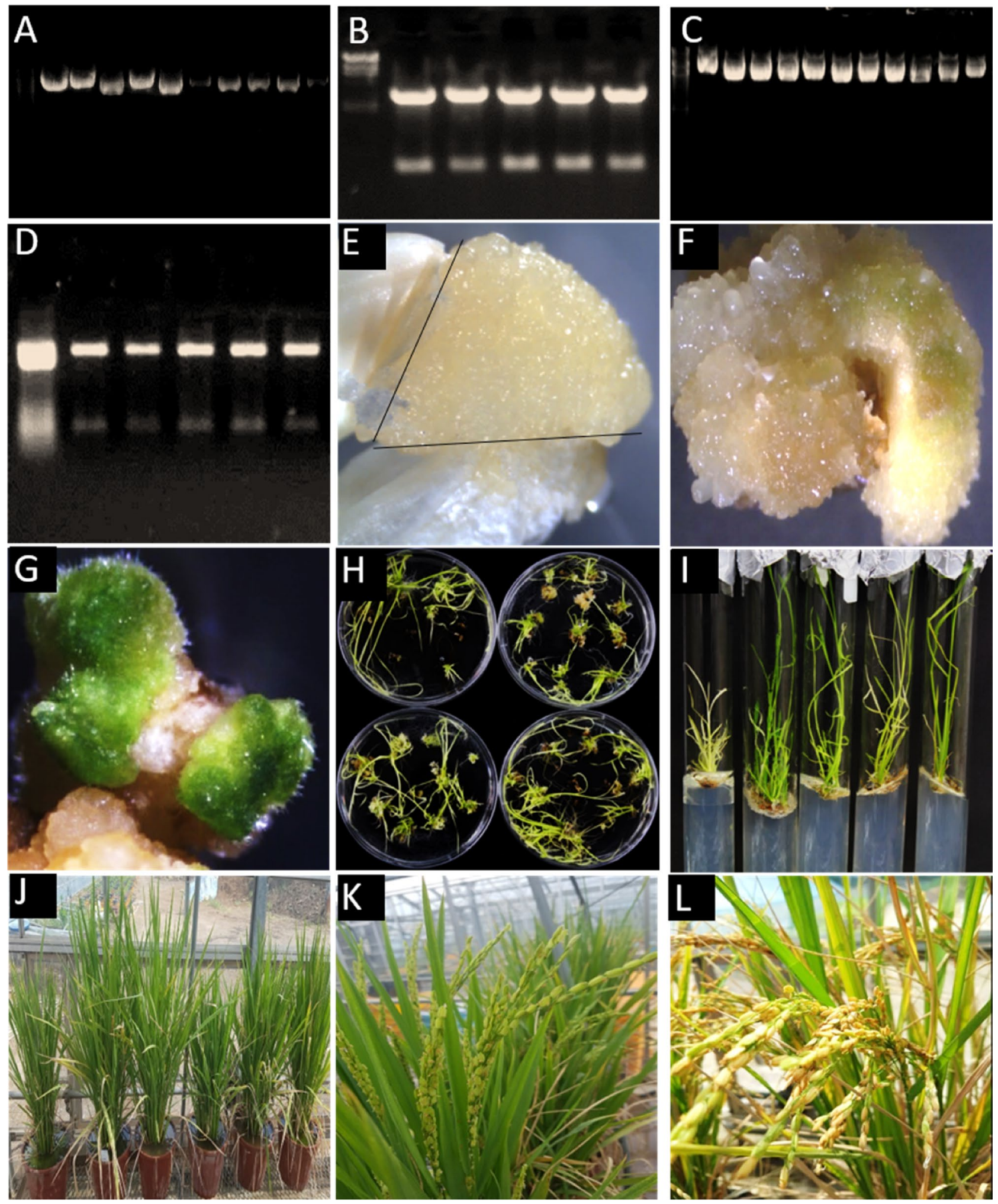

Figure 1. Cloning and development of $O s C M$-overexpressing line. (A) Cloning into E. coli. (B) Double digestion of cloned plasmid isolated from E. coli. (C) Cloning into Agrobacterium. (D) Double digestion of cloned plasmid isolated from Agrobacterium. (E-L) Developmental stages of transgenic line through callus culture. 


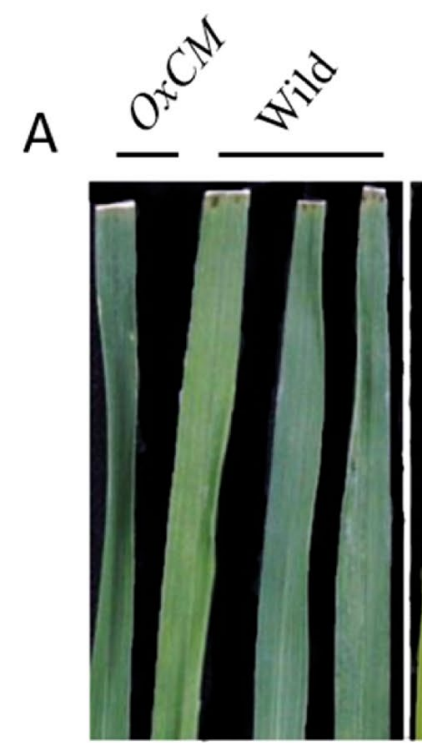

1Week
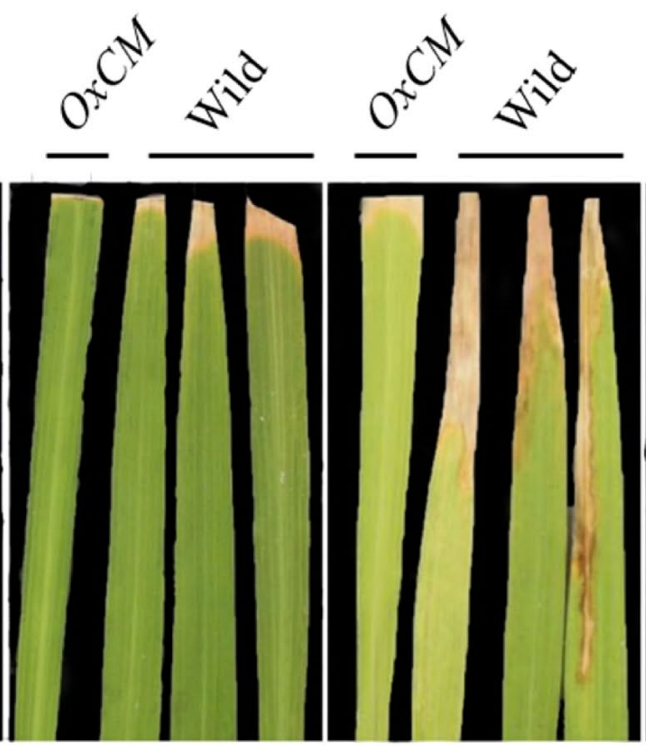

2Week

3Week
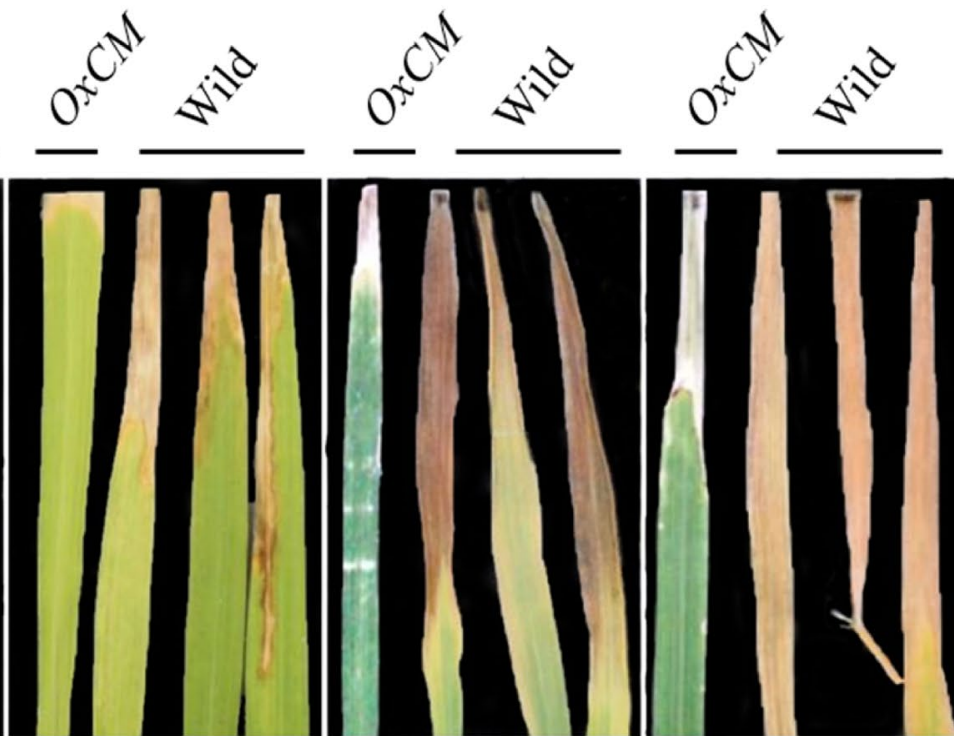

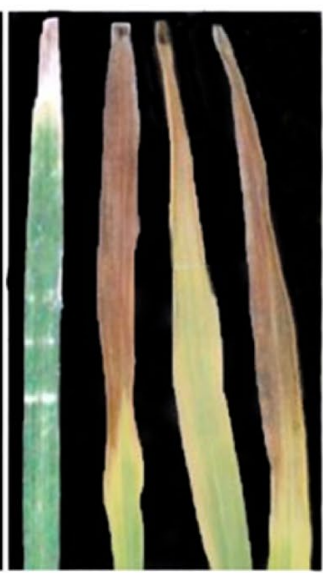

4Week

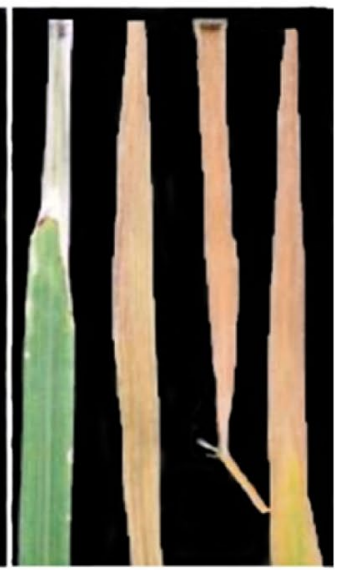

5Week

B

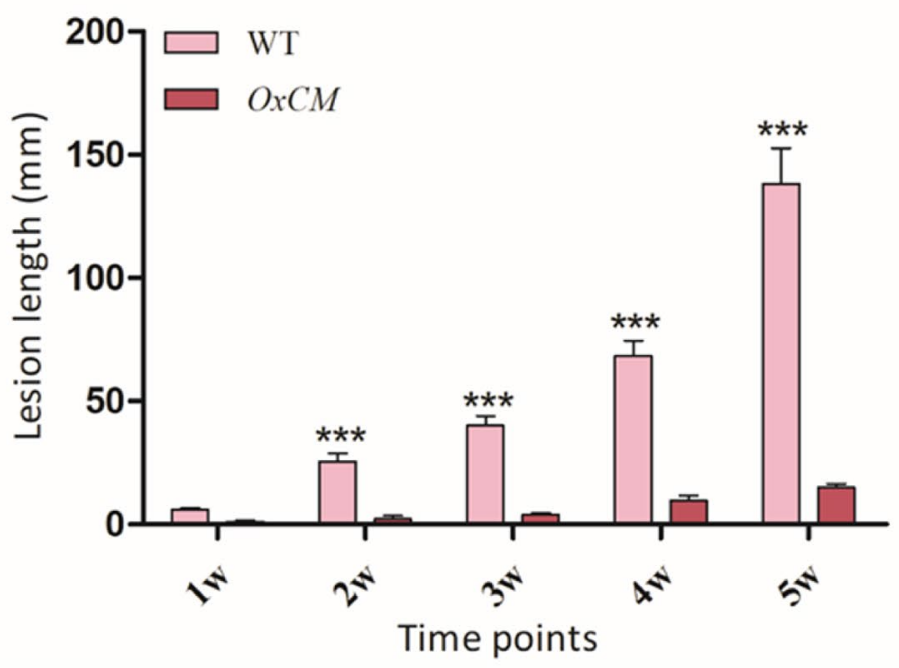

Figure 2. Phenotypic validation of pathogen infection. (A, B) Image and graphical representation of lesion length in response to pathogen infection, respectively. Bars represent mean \pm standard deviation, while asterisks indicate a significant difference ( $p<0.05$, two-way ANOVA, Bonferroni posttest). $1 w, 2 w, 3 w, 4 w$, and $5 w$ represent time points for obtaining data (in weeks).

cantly expressed in the $O x C M$ line as compared to the WT plants (Fig. 3B). These results show that OsCM is positively involved in pathogen resistance. We further investigated Phe and Tyr accumulation in WT and OxCM plants under Xoo stress, as the CM activity enhances Phe and Tyr biosynthesis. Our results showed that Phe was significantly increased $83 \%, 62 \%$ and $52 \%$ after 6,12 and 24 h respectively in OxCM infected plants compared with WT infected plants (Fig. 3C). On the other hand, Tyr accumulation was the same in both the WT and transgenic plants after $1 \mathrm{~h}$ post-infection, but the accumulation was more reduced in WT as compared to OxCM plants with the passage of time (Fig. 3D). These results suggested that, during BLB infection, OsCM expression upregulates Phe biosynthesis while down regulating Tyr biosynthesis.

OsCM regulates aromatic amino acid biosynthesis genes under stressed conditions. To shed light on the genes which are involved in AAAs in the WT and OxCM plants under Xoo stress, we compared the transcript abundance of prephenate dehydratase $(P D T)$, prephenate aminotransferase $(P A T)$, aromatic amino acid aminotransferase $(A A A A T)$, and arogenate dehydratase $(A D T)$ genes, which are involved in AAA biosynthesis, by quantitative PCR (Fig. 4). We observed different expression level of these genes in WT and OxCM plants in Xoo-infected as well as uninfected plants. The relative expression of the PDT gene was significantly increased in OxCM infected plants compared with that in WT infected plants until $24 \mathrm{~h}$ and was then reduced at $36 \mathrm{~h}$ (Fig. 4A). Meanwhile, the expression of PDT was also increased in OxCM uninfected plants compared 
A $\quad$ B

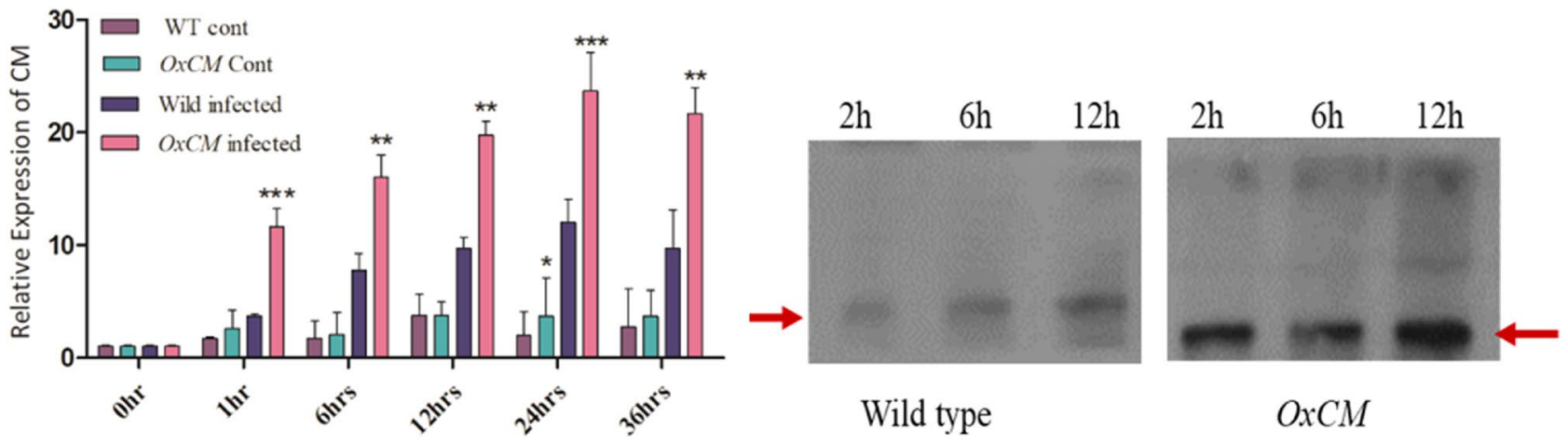

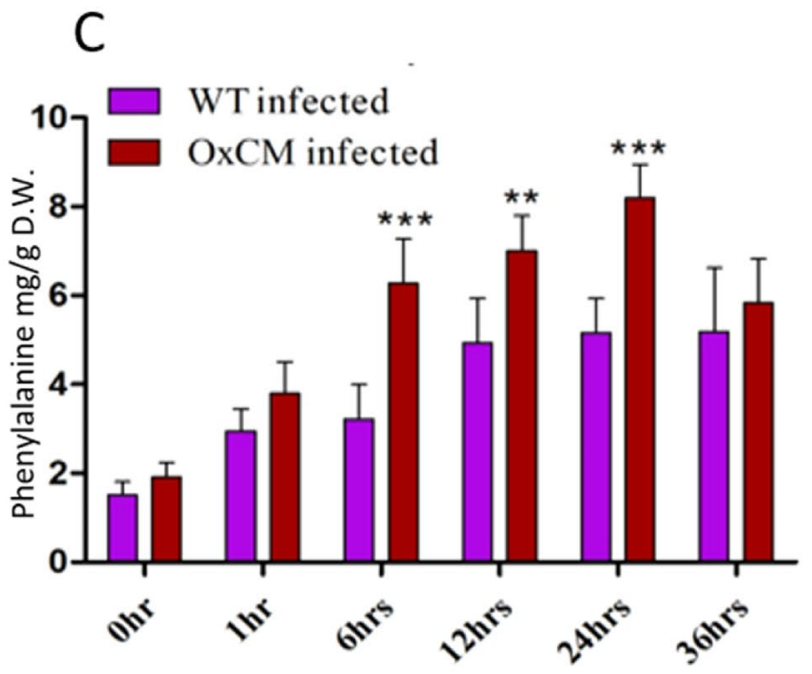

Time points

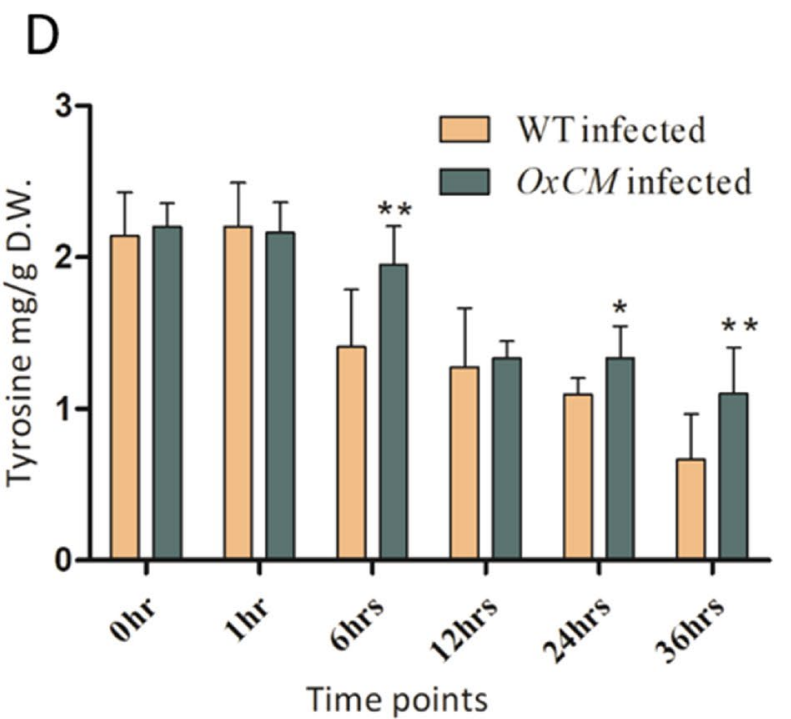

Figure 3. Functional expression of $O s C M$ gene and Phe and Tyr accumulation. Bars represent mean \pm standard deviation, while asterisks indicate a significant difference $(p<0.05$, two-way ANOVA, Bonferroni post-test). $0 \mathrm{~h}$, $1 \mathrm{~h}, 6 \mathrm{~h}, 12 \mathrm{~h}, 24 \mathrm{~h}$, and $36 \mathrm{~h}$ represent time points when data were obtained (in h). WT cont refers to the WT control, $O x C M$ cont refers to the CM-overexpressing control line, wild infected is the WT infected with BLB, and $O x C M$ infected is the CM-overexpressing line infected with BLB. (A) Relative expression of the OsCM gene in WT and overexpressing control and infected plants. (B) Protein expression in the WT and OxCM line at 2, 6 , and $24 \mathrm{~h}$ after infection with BLB. The provided (B) is cropped due to the multiple samples blotting on same $\mathrm{X}$-ray film due to time and resources limitation, the original non-processed picture is given in Supplementary Figure S1. (C, D) Phenylalanine and tyrosine quantification in WT and OxCM infected plants.

with that in WT uninfected plants, which suggested that overexpression of the OsCM gene also activates the PDT gene involved in the catalysis of prephenate into phenylpyruvate. Unlike PDT, PAT was initially ( $1 \mathrm{~h})$ upregulated but was gradually down regulated in both $O x C M$ infected plants and WT infected plants; however, the expression level remained higher in $O x C M$ plants than in WT throughout $36 \mathrm{~h}$ (Fig. 4B). However, PAT expression was significantly higher in $O s C M$-overexpressing uninfected plants than in WT uninfected ones. These results suggested that induction of the PAT gene decreased in response to Xoo infection in both WT and OxCM plants, while under normal conditions, $O x C M$ plants exhibit increased PAT expression compared with WT plants. We assumed that both $P D T$ and $P A T$ act antagonistically during Xoo infection. Similarly, $A A A A T$, which is involved in the regulation of phenylpyruvate conversion into Phe, showed an expression pattern similar to PDT. AAAAT was significantly expressed in $O x C M$ infected plants compared with that in WT infected plants (Fig. 4C). However, the expression was reduced in $O x C M$ uninfected plants compared with that in WT uninfected plants. Unlike $A A A A T, A D T$ was expressed in $O x C M$ infected plants compared with that in WT infected plants until $6 \mathrm{~h}$ after the inoculation of Xoo, but was then significantly reduced (Fig. 4D). On the other hand, similar to PAT, ADT was also upregulated in WT and OxCM uninfected plants, but the expression of $O x C M$ was lower than in WT plants. Figure $4 \mathrm{E}$ shows a graphical representation of the effects of OsCM-overexpression on all of the four genes (PDT, PAT, $A A A A T$, and $A D T$ ) under stress conditions. It was assumed that, under stress conditions, the 

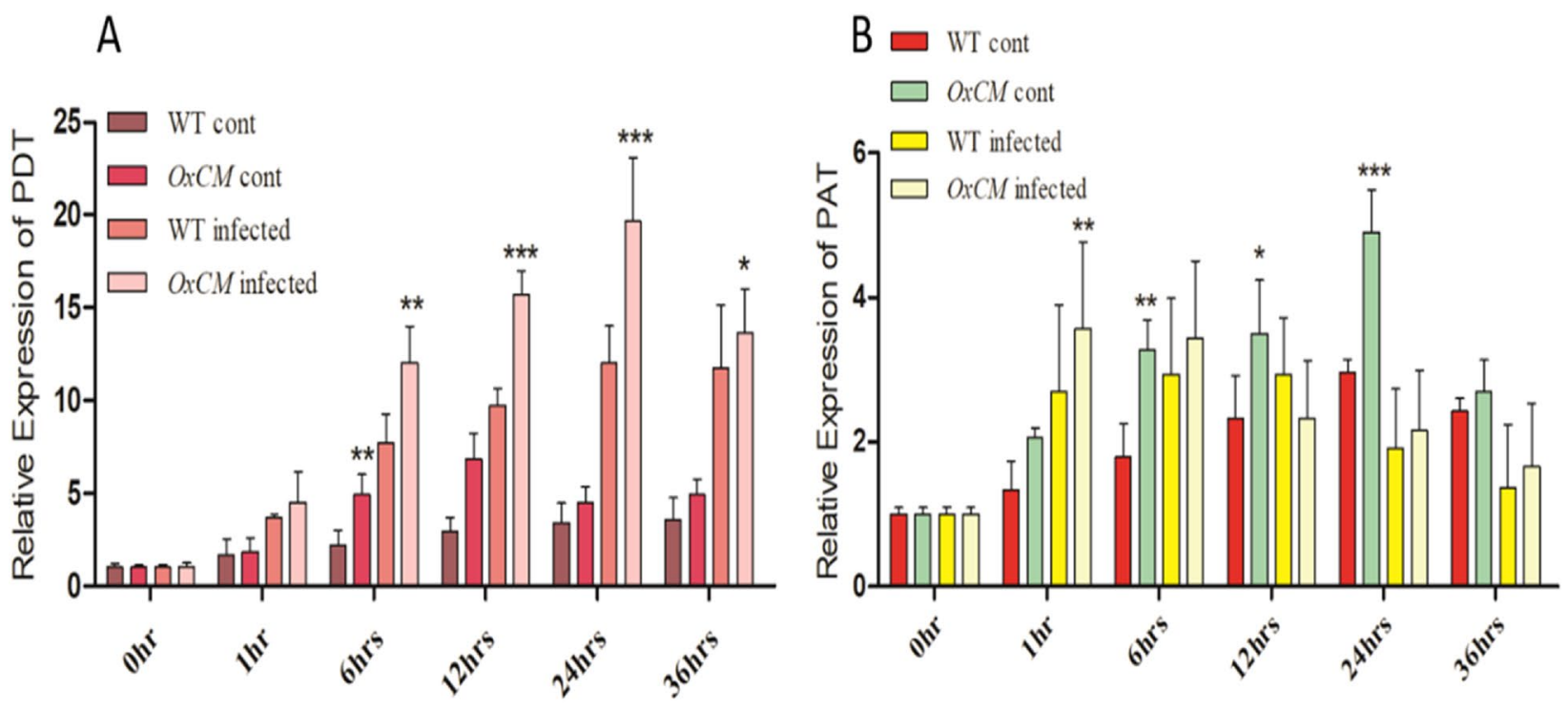

C

D
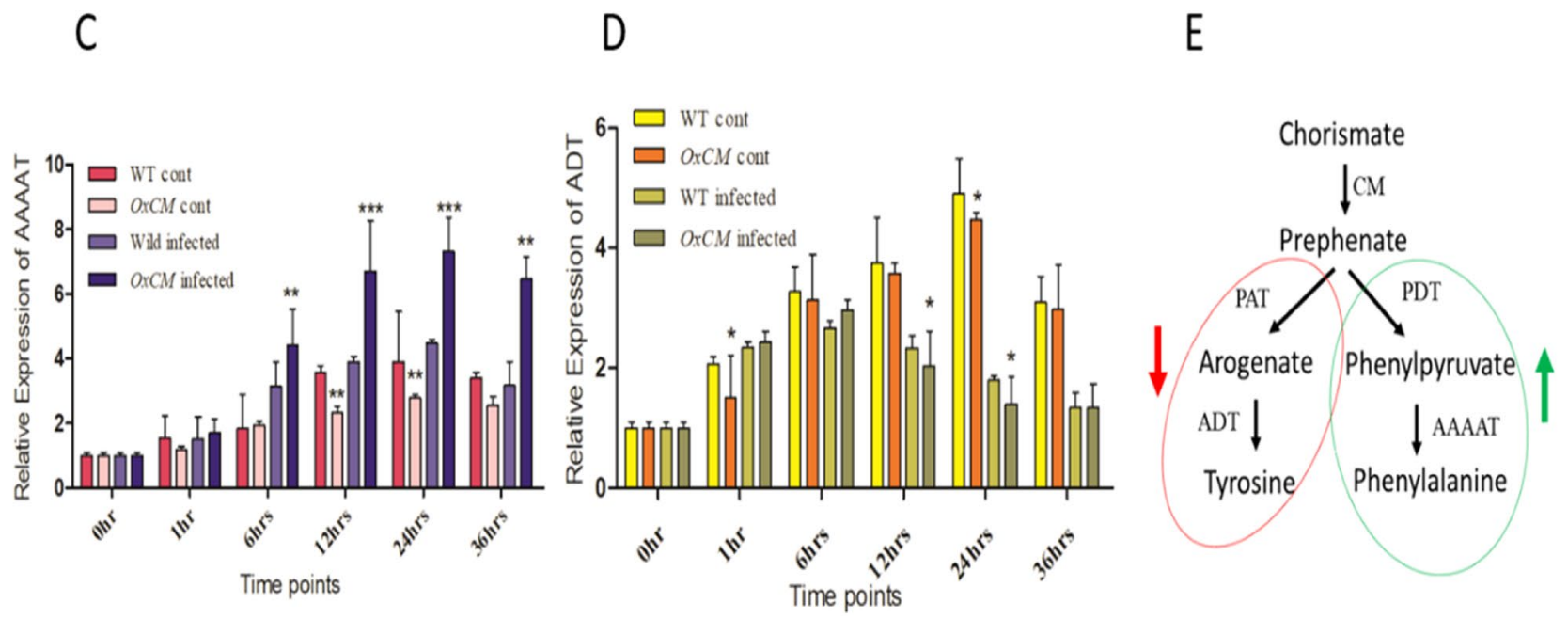

Figure 4. Regulation of downstream genes by overexpression of chorismate mutase. Bars represent mean \pm standard deviation, while asterisks indicate a significant difference $(p<0.05$, two-way ANOVA, Bonferroni post-test). $0 \mathrm{~h}, 1 \mathrm{~h}, 6 \mathrm{~h}, 12 \mathrm{~h}, 24 \mathrm{~h}$, and $36 \mathrm{~h}$ represent time points at which data were obtained (in hours). WT cont refers to the WT control, $O x C M$ cont is the CM-overexpressing control line, wild infected is the WT infected with BLB, and OxCM infected is the CM-overexpressing line infected with BLB. (A) PDT is prephenate dehydratase, (B) PAT is prephenate aminotransferase, (C) AAAAT is the aromatic amino acid aminotransferase, and (D) is the arogenate dehydratase gene relative expression among the WT and OsCMoverexpressing infected and control plants. (E) A schematic representation of the related gene expression. A downward arrow indicates down regulation of $P A T$ and $A D T$, while an upward arrow indicates up regulation of $P D T$ and $A A A A T$ genes at the same time.

overexpression of OsCM down regulates the genes involved in the Tyr biosynthesis pathway while up regulating the genes involved in the Phe biosynthesis pathway.

JA and SA cross-talk in OxCM and WT plants under pathogen infection. To further verify the efficiency by which $O x C M$ confers tolerance to Xoo infection with respect to that of WT plants, we evaluated the SA and JA accumulation in both types of plant under Xoo infection at six time points within 0-36 h. The results demonstrated that JA was significantly reduced in OxCM plants compared with that in WT plants (Fig. 5A). In the first hour of infection, the accumulation was increased in both types of plant, but later on it was consistently reduced. In the first hour of infection, about $70 \mathrm{ng} / \mathrm{g}$ D.W accumulated in WT plants, which was reduced to $30 \mathrm{ng} / \mathrm{g}$ D.W. which was 75\%, after $36 \mathrm{~h}$. Likewise, in the first hour of infection, $44 \mathrm{ng} / \mathrm{g}$ D.W. JA accumulated, which was reduced to $23 \mathrm{ng} / \mathrm{g}$ D.W. which was $47 \%$, after $36 \mathrm{~h}$. In contrast to JA, SA was significantly and con- 


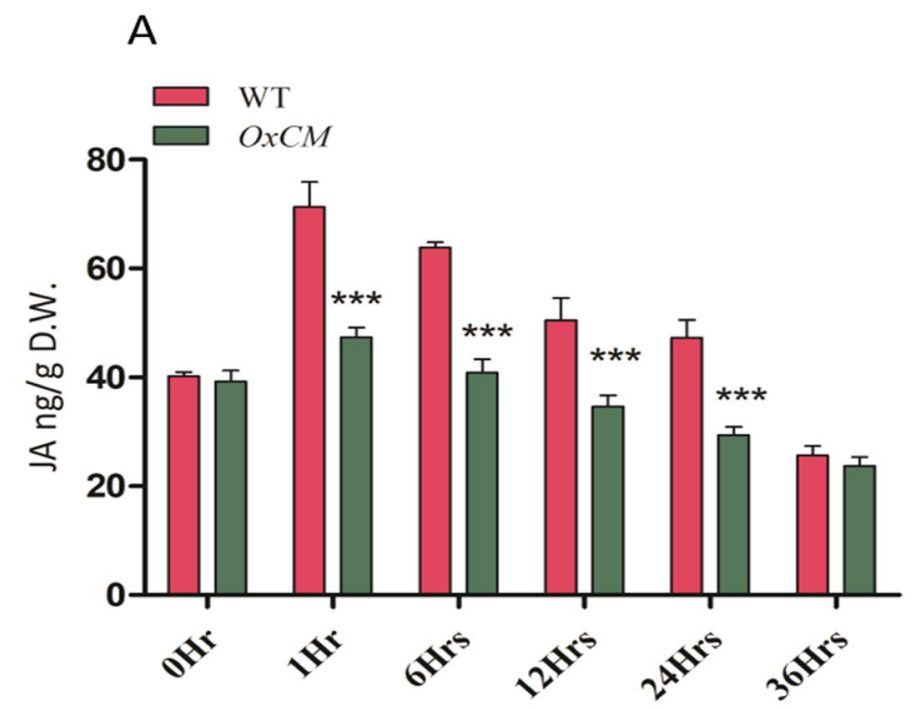

B

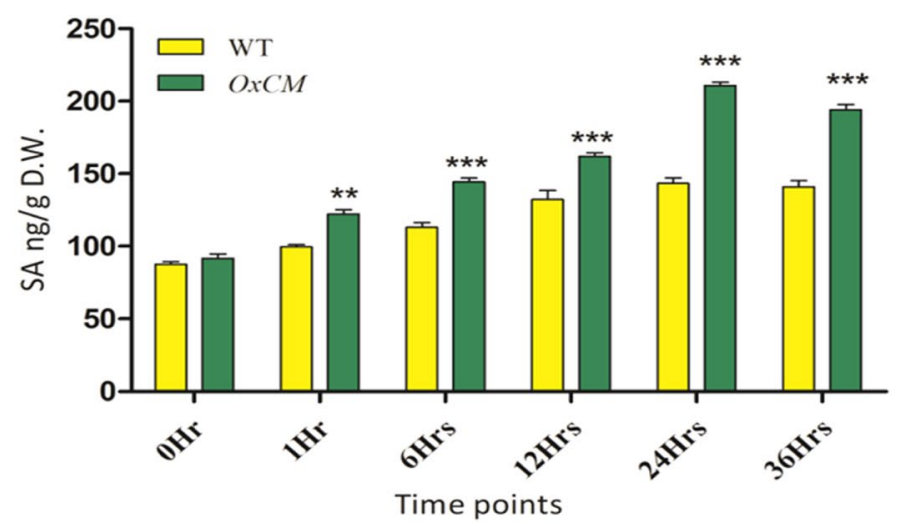

Figure 5. JA and SA accumulation in pathogen response. Bars represent mean \pm standard deviation, while asterisks indicate a significant difference ( $p<0.05$, two-way ANOVA, Bonferroni post-test). $0 \mathrm{~h}, 1 \mathrm{~h}, 6 \mathrm{~h}, 12 \mathrm{~h}$, $24 \mathrm{~h}$, and $36 \mathrm{~h}$ represent time points at which data were obtained (in h). WT refers to WT infected and $O x C M$ is the CM-overexpressing line infected with BLB. (A) JA accumulation and (B) SA accumulation in WT and OxCM infected plants.

tinually enhanced in $O x C M$ plants with increasing infection time, compared with that of WT plants (Fig. 5B). SA accumulated from 1 to $24 \mathrm{~h}$ in the range of $125-210 \mathrm{ng} / \mathrm{g}$ D.W. which was $68 \%$ however, from $36 \mathrm{~h}$ of infection, the SA level started to decrease. These results confirmed that JA and SA are regulated antagonistically.

OsCM positively regulates the expression of disease resistance genes. It has been reported that NPR1 is involved in Xoo resistance via regulation of the defense-related gene $X a 7^{25,26}$. Thus, we examined the pattern of expression of NPR1 and Xa7 in the infected $O x C M$ line with respect to infected WT plants. The results showed that NPR1 was significantly induced in the $O x C M$ infected plants compared with the level in WT infected plants and the expression increased with increasing infection time until $24 \mathrm{~h}$ (Fig. 6A). After $24 \mathrm{~h}$ of infection, the NPR1 expression was reduced in infected and uninfected OxCM and WT plants. However, the NPR1 gene expression was also higher in $O x C M$ uninfected plants than in WT uninfected plants. Likewise, the $\mathrm{Xa7}$ gene also showed the same pattern of expression as NPR1. The Xa7 expression was also higher in OxCM infected plants than in WT infected ones (Fig. 6B). The expression gradually increased with increasing infection time until $24 \mathrm{~h}$. The results suggest that overexpression of $O s C M$ in rice plants increases BLB tolerance in terms of regulating the NPR1 gene, which in turn regulates the defense-related gene $\mathrm{Xa}$.

OsCM enhances lignin accumulation and amino acid content upon BLB stress. We studied lignin and total amino acid contents against Xoo stress in $O x C M$ and WT plants, as lignin exhibits regulatory functions under biotic as well as abiotic stresses, while amino acids are involved in the biosynthesis of various secondary metabolites, which are directly involved in biotic stresses ${ }^{27,28}$. The results showed that more lignin and total amino acids were accumulated in the OxCM infected plants as compared to WT infected plants (Fig. 7A,B). Continuous increases of lignin and amino acids were found upon continued infection. Lignin was increased 


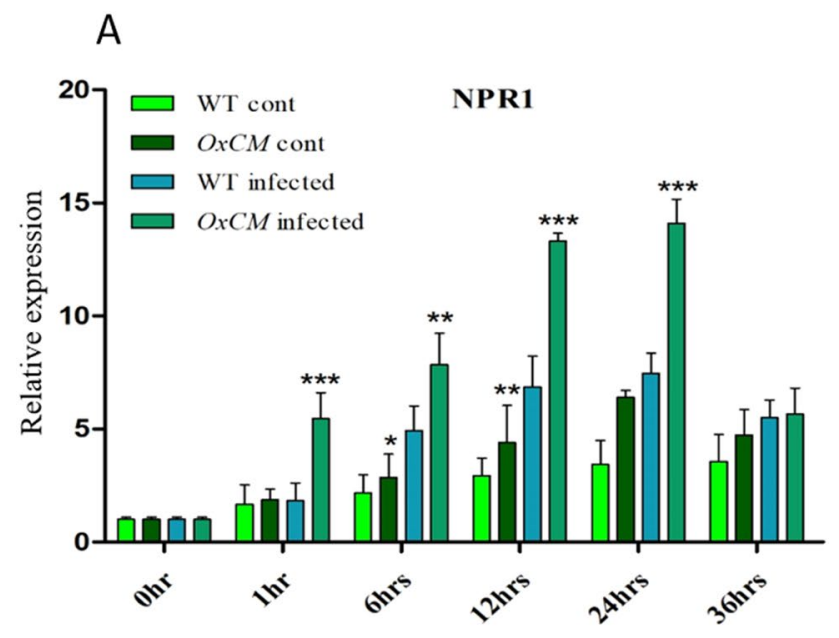

B

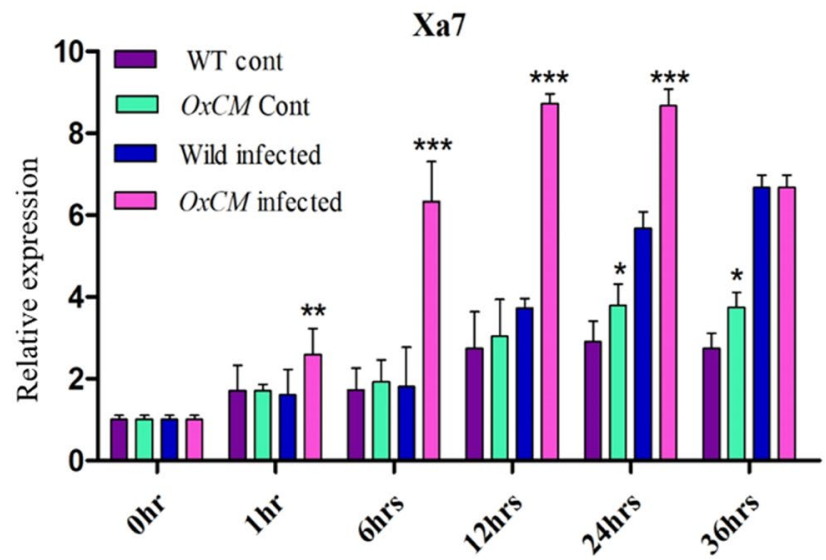

Figure 6. Expression of NPR1 and Xa7 under pathogen inoculation. Bars represent mean \pm standard deviation, while asterisks indicate a significant difference ( $p<0.05$, two-way ANOVA, Bonferroni post-test). $0 \mathrm{~h}, 1 \mathrm{~h}, 6 \mathrm{~h}$, $12 \mathrm{~h}, 24 \mathrm{~h}$, and $36 \mathrm{~h}$ represent time points at which data were obtained (in hours), WT refers to WT control, $O x C M$ cont is CM-overexpressing control line, wild infected is the WT infected with BLB, and OxCM infected is the CM-overexpressing line infected with BLB. (A, B) Relative expression of NPR1 and Xa7 genes, respectively, among the WT and OsCM-overexpressing control and infected lines.

$115 \%$ from $13 \mathrm{mg} / \mathrm{g}$ D.W. to $28 \mathrm{mg} / \mathrm{g}$ D.W. from 0 to $36 \mathrm{~h}$ of infection in $O x C M$ plants. Similarly, the concentration of amino acids in OxCM infected plants increased 21\% from 107 to $130 \mathrm{mg} / \mathrm{g}$ D.W. over $36 \mathrm{~h}$ of infection. However, significance differences in both lignin and amino acids appeared after $6 \mathrm{~h}$ of infection. These results show that Xoo infection regulates lignin and total amino acids in rice plants.

\section{Discussion}

AAAs such as Phe and Tyr are central molecules in plant metabolism and synthesized in the shikimate pathway from the common precursor chorismate. The shikimate pathway connects primary metabolites to secondary metabolites via chorismate being the end product of shikimate, which initiates the synthesis of AAAs that in turn enhances secondary metabolites ${ }^{3}$. Phe and Tyr induces cinnamic acid which is the precursors of phenylpropanoid ${ }^{9}$. Plants have adopted several defense signaling pathways to mitigate severe environmental conditions and pathogenic attack, such as by altering secondary metabolites ${ }^{29}$. The modulation of secondary metabolites like phenylpropanoids against biotic and abiotic stresses is a clue to the involvement in stress tolerance ${ }^{30}$. A wide range of phenolic compounds are produced from phenylpropanoids such as flavonoids, isoflavonoids, anthocyanins, plant hormones, phytoalexins, and lignins ${ }^{31,32}$.

In current study, OsCM gene was functionally evaluated by generating an overexpressing line using Agrobacterium-mediated transformation in rice plants. The innate immunity of plants was altered upon infection of $\mathrm{BLB}$ and the suppression and induction of OsCM activity were confirmed by biological assays. The phenotypic evaluation of lesion length demonstrated that $O x C M$ plants were highly tolerant of BLB stress. Evaluation of the two AAAs, Phe and Tyr, showed that they were adversely altered during BLB stress, which suggested that they are participants in pathogen tolerance. The results showed that Phe accumulation was increased in the $O x C M$ line, while Tyr was decreased in Xoo after inoculation (Fig. 3C,D). We predicted that the alterations of Phe and Tyr 
A

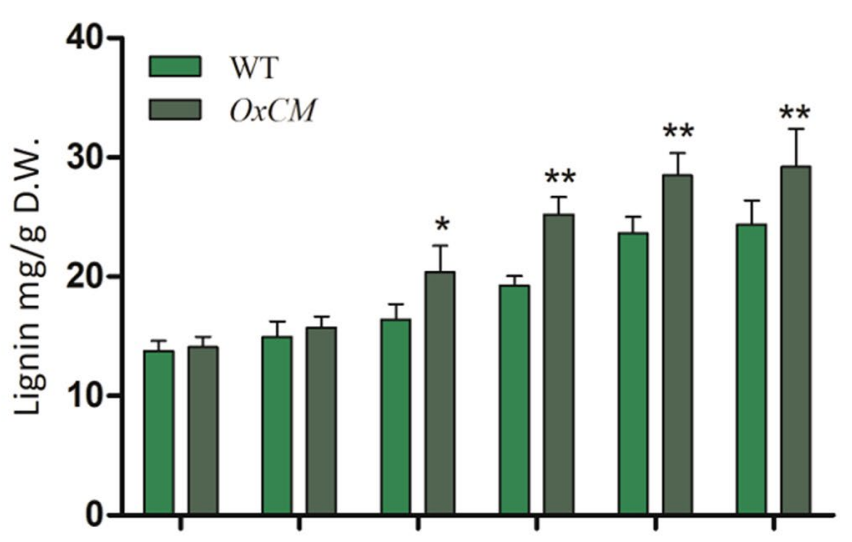

B

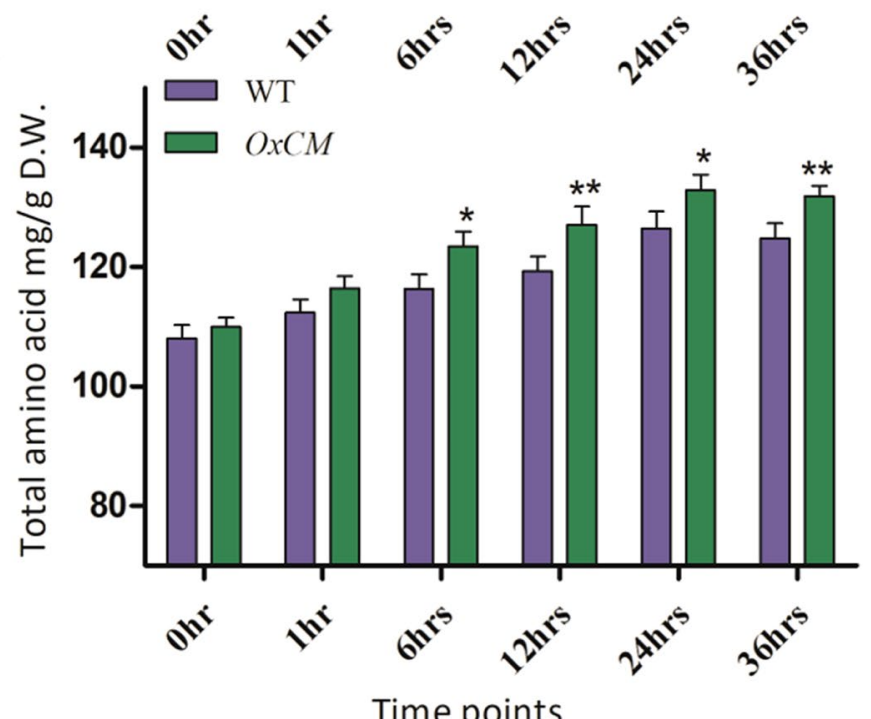

Figure 7. Lignin and amino acid accumulation upon pathogen stress. Bars represent mean \pm standard deviation, while asterisks indicate a significant difference ( $p<0.05$, two-way ANOVA, Bonferroni post-test). $0 \mathrm{~h}$, $1 \mathrm{~h}, 6 \mathrm{~h}, 12 \mathrm{~h}, 24 \mathrm{~h}$, and $36 \mathrm{~h}$ represent time points at which data were obtained (in h). WT refers to WT infected and $O x C M$ is the CM-overexpressing line infected with BLB. (A) Lignin accumulation and (B) total amino acid accumulation in WT and OxCM infected plants.

were due to induction of the $O s C M$ gene because the $O s C M$ gene was significantly induced in the $O x C M$ line at the transcriptomic and proteomic levels (Fig. 3A,B), which enhanced the accumulation of Phe in the transgenic line. Phe is considered to be the chief AAA accumulated in plants under normal conditions, being at a level higher than Tyr and Trp, and absorbing about $30 \%$ of photosynthetic carbon to produce phenylpropanoids ${ }^{33}$. We assumed that the induction of Phe under BLB stress in OxCM plants, enhanced the accumulation of downstream metabolites, which increased Xoo tolerance. A previous study showed that induction of the derivatives of Phe and Tyr (phenylpropanoids) under stress conditions was enhanced due to up regulation of the Phe catabolic enzyme, $P A L$, which uses Phe as a substrate ${ }^{34}$. Supported by the high accumulation of Phe in $O x C M$ infected plants, the results showed that the genes downstream of $O s C M$ such as $P D T$ and $A A A A T$ were positively regulated, whereas the genes responsible for Tyr biosynthesis such as $P A T$ and $A D T$ were negatively regulated (Fig. 4). The fold change of Phe was much greater than that of Tyr, which shows that Phe is highly involved in the biosynthesis of phenylpropanoids in response to pathogenic attack. A previous study confirmed that an increasing Phe level in petunia flowers increases the production of phenylpropanoids ${ }^{35}$. The signaling of a reduction in Tyr corresponding to Phe in BLB stress is not well known, but it was predicted that Tyr is not efficiently involved in stress mitigation compared with Phe.

Plant hormones are dynamic regulators of plant responses to environmental pressure by participating external stimuli with complex monitoring systems. SA is an important part of plant defense and is well known for its defensive role in plant defense system against pathogens ${ }^{36}$. SA has a vital role in rice defense system in response to Xoo, and enhances both basal defense and the hypersensitive response during Xoo infection in rice ${ }^{20}$. The SA signaling pathway might be involved in the regulation of glucosinolate, which is hydrolyzed by SA to various degradation products that play significant part in interactions with pathogens ${ }^{37}$. The current study investigated the regular increase of SA in rice plants in response to continued Xoo infection, and the SA accumulation was 
significantly higher in $O x C M$ plants than in WT. This investigation proved that OsCM is significantly involved in the biosynthesis of SA. In most plants, SA can be synthesized by two key regulatory enzymes, $P A L$ and ICS, whereas PAL uses phenylalanine and ICS uses chorismate as a substrate ${ }^{38}$. Although ICS is involved in SA accumulation in response to some plant stresses ${ }^{11,39}$, the pathogen and other stress-induced SA is mostly derived from the $P A L$-catalyzed pathway ${ }^{40}$. A previous study showed that Arabidopsis $P A L$ mutant accumulated more SA than ICS mutant, which suggested that, in Arabidopsis, ICS is the key contributor to pathogen-induced SA biosynthesis ${ }^{11}$. However, these clarifications are based on independent analysis of either the PAL or the ICScatalyzed pathway, and the comparative contributions of PAL vs. ICS to SA biosynthesis and pathogen defense have not been instantaneously assessed for any plant system. Although the PAL and ICS pathways are equally significant for SA biosynthesis, suppression of either pathway is enough to compromise SA biosynthesis in response to pathogenic attack. In the present study, we did not evaluate the relative expression of ICS, but the higher accumulation of Phe and SA suggested that PAL is sufficiently involved in the biosynthesis of SA in response to BLB stress. A previous study showed that SA regulation in response to stress may be feedback-regulated by the metabolites of biochemical pathways. This inference was supported by the feedback-regulation of CM by phenylalanine and feedback allosteric regulation assessed in amino acid biosynthesis ${ }^{41,42}$. Notably, the bacterial pathogen infection increased the expression level of the key leaf-expressed PAL isoform instead of ICS in soybean. Another previous study suggested that either $P A L$ or ICS knockout eliminated pathogen-induced production of SA in soybean, which implied that the expression of ICS is not a requirement for SA biosynthesis ${ }^{38}$. It is possible that enhanced $P A L$ induction as related to its role as a chief regulator of the phenylpropanoid pathway, which is well known to participate in defense ${ }^{43-45}$. Similar to SA, JA also has a main part in mitigating pathogen-related stress. However, SA and JA signaling pathways were reported to interact antagonistically against biotic stress ${ }^{46}$. Unlike SA, the JA accumulated in OXCM plants was efficiently reduced with increasing Xoo infection time, compared with that in the WT (Fig. 5A). Studies have shown that SA facilitates the down regulation of JA-responsive genes like lipoxygenase 2 ( $L O X 2$ ), vegetative storage protein, and PDF1.24. Pathogenic infection manipulates the defense-related regulatory network in plants in terms of phytohormone accumulation, which causes hormonal imbalance and activates untimely defense responses ${ }^{47}$. Previous studies showed that the synthesis of coronatine- 1 JA-Ile mimic by Pseudomonas syringae pv. tomato (Pst) bacteria altered the stimulation of JA-dependent defense responses, leading to the inhibition of SA-dependent defense responses ${ }^{48,49}$. Plants usually resist a diverse range of attackers in the natural environment via regulating complex defense mechanisms to modulate effective defense responses against pathogens. However, the mechanism by which plants prioritize one response over another is unknown. This interpretation shows that not all pathogens activate JA signaling in plants, such as Bemisia tabaci enhancing SA and suppressing JA accumulation in Arabidopsis ${ }^{50}$, similar to our findings. This means that neither SA nor JA is more important, but both hormones are equally important for pathogen resistance. Positive or negative cross-talk between SA and JA may be induced depending on the pathogen ${ }^{51}$.

This study was extended to focus on the relative expression levels of NPR1 and Xa7 genes. NPR1 is one of the essential regulatory tools of SA signaling, which interacts with TGA transcription factors that are responsible for the activation of SA-responsive $P R$ genes $^{52}$. NPR1 in rice enhances tolerance to rice bacterial blight (Xanthomonas oryzae pv. oryzae) and rice blast fungus (Magnaporthe grisea), and also activates $P R$ gene induction and regulates $\mathrm{SAR}^{22} . \mathrm{Xa7}$ is a $P R$ gene that enhances Xoo resistance in rice plants at high temperature, whereas resistance change due to other $R$ genes is usually suppressed ${ }^{53}$. Xa7 regulates hypersensitivity and localized host cell death to control pathogenic infection in the plants ${ }^{54}$. It was previously shown that Xa7 expression suppressed the expression of ABA-related genes, which signal antagonistically with $\mathrm{SA}^{55}$. Our results suggested that SA and $X a 7$ interact with each other and are positively regulated in response to pathogens. Furthermore, our study revealed that the expression of $N P R 1$ and $X a 7$ was highly induced in the $O x C M$ line under Xoo stress, which was consistent with the higher SA accumulation (Fig. 6). A previous investigation evaluated that the enhancement of SA accumulation in pathogen-infected tissues resulted in enhancement of the PR gene expression that modulate the resistance of a broad range of pathogens ${ }^{46}$. NPR1 plays an essential part in SA-JA cross-talk because the NPR1 Arabidopsis plants were compromised in terms of the SA-mediated suppression of JA-responsive gene expression $^{56}$. Various WRKY transcription factors downstream of NPR1 play key roles in altering SA-dependent defense responses in plants $^{21}$. SA's association with heme-containing enzymes, such as catalase, result in adequate redox stress to initiate the release of monomers of NPR1 and their entry into the nucleus ${ }^{57}$.

Lignin and amino acids are essential modulators of stress responses in plants produced via the shikimate pathway $^{58}$, associated with the $P A L$ pathway. Along with the accumulation of SA, PAL activity also offers a precursor (cinnamic acid) for lignin biosynthesis in response to pathogen infection ${ }^{59}$. We investigated that lignin quantification in response to Xoo infection was higher in OxCM rice plants than in the WT. It was assumed that overexpression of the OsCM gene was involved in the regulation of lignin via the alteration of $P A L$ activity. In $P A L$-knockdown Brachypodium plants, lignin accumulation was decreased up to $40 \%$, which enhanced pathogen susceptibility ${ }^{60}$. Lignin accumulation in Arabidopsis PAL1, PAL2, PAL3, and PAL4 mutants was decreased from 20 to $25 \%$ compared with that in WT plants, while the same plants also showed a reduced level of SA and enhanced pathogen susceptibility ${ }^{61}$. Although lignification enhances the toughness of the cell wall in response to pathogenic attack, the free radical-mediated polymerization of lignin precursors in intercellular spaces might also lignify pathogenic structures. Lignin hydrophobicity enables solute transformation in the vascular tissues and reduces water loss during evapo-transpirative processes. Similarly, total amino acid accumulation was enhanced in OxCM infected plants compared with that in WT plants because the higher accumulation of amino acids is essential for plants to respond to stress in term of ROS scavenging behavior, as well as potential regulatory and signaling molecules ${ }^{62,63}$. The higher accumulation of total amino acids in Xoo-infected $O x C M$ plants suggested that the OsCM gene of the shikimate pathway is significantly involved in the accumulation of total amino acids in response to pathogenic attack. 


\section{Materials and methods}

Generation of $O s C M$ transgenic rice line. Rice plants (Cheongcheong) were selected for transformation and further study. The seeds were sterilized with $3 \%$ hypochlorite for $10 \mathrm{~min}$ and then incubated at $32{ }^{\circ} \mathrm{C}$ in water until they started to germinate, with their water changed every day. The germinated seeds were grown in a greenhouse and the samples were collected after 3 weeks for total RNA isolation. Total RNA was isolated using RNeasy Plant Mini Kit from Qiagen and the open reading frame (ORF) of OsCM (MH752192) was amplified using gene primers. The OsCM was cloned into the cloning vector pENTR/D-TOPO (pENTR Directional TOPO cloning kit; Invitrogen) and then into the PSB11 expression vector using the Gateway cloning system (Gateway LR Clonase enzyme mix kit; Invitrogen). The entry clone was first transferred into DH5a E. coli and then transferred into Agrobacterium cells LBA4404 (Takara) via the heat shock method and spread on hygromycin-containing LB medium. Both inserts were confirmed through double digestion using Not1 and Ascl and BamH1 and Xhol, respectively. $C M$-overexpressing $(O x C M)$ rice lines were developed through a callus culture technique. Seeds of good quality were dehulled, sterilized with $3 \%$ hypochlorite for $10 \mathrm{~min}$, washed three times, sterilized again with $70 \%$ ethanol for $5 \mathrm{~min}$, washed again with $\mathrm{ddH}_{2} \mathrm{O}$, and dried in laminar flow. Dried seeds were inoculated in callus induction medium at 10-15 seeds per plate and placed in the dark for 12 days. The induced callus was further pre-cultured on callus induction medium for 3 days under dark conditions. At the same time, the OsCMinserted Agrobacterium cells were grown on selection medium for transformation into callus. Agrobacterium cells were pelleted and resuspended in MS medium fortified with acetosyringone and the callus was immersed in the suspension for $30 \mathrm{~min}$ with continuous shaking. After incubation in Agrobacterium cells, the callus was dried for $30 \mathrm{~min}$ on sterilized filter paper and then inoculated into co-cultivation medium for 3 days in the dark. The excessive growth of Agrobacterium in the callus was controlled by washing three times with $500 \mathrm{mg} / \mathrm{l}$ carbenicillin, dried for $30 \mathrm{~min}$, and again inoculated into the first selection medium containing $50 \mathrm{mg} / \mathrm{l} \mathrm{hygromycin}$. The callus was inoculated three times into selection medium under light conditions $(16 / 8 \mathrm{~h}$ photoperiod). After three periods of selection, the callus was transferred into regeneration medium for 10 days in the dark. In the second phase, the callus was transferred to new identical medium and placed under light conditions until the plantlets developed; in the third phase, the plantlets were put in a test tube on the same medium to develop roots. After 20 days in a test tube, the plants developed appropriately and were transferred to soil in pots.

Inoculation of BLB and lesion length measurement. Wild-type and $O x C M$ plants were grown in a greenhouse, following the described method. The K3a strain of Xanthomonas oryzae (Xoo) was inoculated into wild-type as well as $O x C M$ plants using the leaf clipping method ${ }^{64}$. The experiment was conducted in two sets: one set of wild-type and $O x C M$ plants were infected with Xoo, while the second set remained uninfected and was used as a control. The samples were collected in triplicate $0,1,6,12,24$, and $36 \mathrm{~h}$ after the inoculation of Xoo for further analysis. However, lesion length was measured after each week until 5 weeks after Xoo infection.

RNA isolation and quantitative RT-PCR analysis. Total RNA was isolated from five leaves in triplicate and cDNA was synthesized using the qPCRBIO cDNA Synthesis Kit from PCRBIOSYSTEMS. Quantitative real-time RT-PCR (qRT-PCR) was performed using qPCRBIO SYBR Green Kit from PCRBIOSYSTEM, using cDNAs as templates and gene-specific primers. To normalize the level of relative expression of each gene, actin was used for each reaction and the expression level was calculated in wild-type plants relative to that in $O x C M$ infected ones. The reaction was performed in a $20 \mu \mathrm{l}$ volume containing $7 \mu \mathrm{l}$ of $\mathrm{ddH}_{2} \mathrm{O}, 1 \mu \mathrm{l}$ of primer, $10 \mu \mathrm{l}$ of SYBR green, and $1 \mu \mathrm{l}$ of cDNA, and was repeated in triplicate.

Western blot analysis. To check protein expression in the transgenic line as well as in the wild-type, western blotting was performed by a previously reported optimized method ${ }^{65}$ with slight modifications. Proteins of the OxCM line and the wild-type treated with BLB were collected at three time points: 2,6 , and $12 \mathrm{~h}$ after BLB inoculation. Total protein was isolated with $10 \mathrm{ml}$ of TCA/acetone [10\% trichloroacetic acid (TCA); $0.07 \% \beta-\mathrm{ME}$ in acetone P.A.], by a previously reported method ${ }^{66}$. Equal amounts of protein were boiled for 5 min, separated by $10 \%$ SDS-PAGE at $100 \mathrm{~V}$ for $150 \mathrm{~min}$, and then transferred to an NC membrane (Whatman Japan) by a semidry method running for $90 \mathrm{~min}$ at $19 \mathrm{~V}$ using Trans-Blot DS semi-dry transfer cell (Bio-Rad). The membrane was blotted in TBST ( $0.1 \%$ Tween 20 in TBS) and $5 \%$ non-fat dry milk (w/v) for $2 \mathrm{~h}$ at room temperature. Proteins were further blotted with primary rabbit anti-CM synthase antibodies in $5 \%$ non-fat dry milk $(\mathrm{w} / \mathrm{v})$ in TBST overnight at $4{ }^{\circ} \mathrm{C}$ and subjected to three rinses for 10 min each in TBST solution. The membrane was then incubated with Gt anti-Ms IgG (H+L) secondary antibody (Invitrogen, USA) at a dilution of 1:1000 for $2 \mathrm{~h}$ at room temperature and rinsed three times for 10 min each in TBST solution. The blot was developed by Amersham ECL (GE Healthcare, UK) and protein bands were exposed on X-ray film.

Quantification of endogenous SA and JA hormones. To assess SA and JA accumulation in wildtype and $O x C M$ plants in response to Xoo stress, we analyzed both of these hormones. Leaves of the plants were collected in liquid nitrogen after each time point and stored at $-80^{\circ} \mathrm{C}$. For SA analysis, frozen leaves were lyophilized and crushed into a fine powder in liquid nitrogen using a modified version of a previously reported protocol ${ }^{67}$. The lyophilized powder of each sample $(0.3 \mathrm{~g})$ was extracted with $90 \%$ ethanol and $100 \%$ methanol and centrifuged for $20 \mathrm{~min}$ at $1000 \mathrm{rpm}$. The supernatant was collected and methanol was dried in a vacuum centrifuge and again resuspended in $5 \%$ trichloroacetic acid $(3 \mathrm{ml})$. The supernatant was further mixed with ethyl acetate/cyclopentane/isopropanol (49.5:49.5:1, v/v), and the uppermost organic layer was collected in a $4 \mathrm{ml}$ vial and then dried with nitrogen gas. The extracted SA was analyzed by HPLC, with quantification through fluorescence detection. For JA analysis, freeze-dried leaves $(0.2 \mathrm{~g})$ were homogenized with liquid nitrogen and JA was extracted with acetone and $50 \mathrm{mM}$ citric acid $(70: 30, \mathrm{v} / \mathrm{v})$, following a previously reported protocol ${ }^{68,69}$. 
An internal standard, [9,10-2H2]-9,10-dihydro-JA (20 ng), was also added to the suspension. The extract was kept at low temperature overnight to evaporate highly volatile organic solvents and retain the less volatile fatty acids. The remaining solution was filtered and then extracted with $10 \mathrm{ml}$ of diethyl ether three times. The extract was further loaded onto a solid-phase extraction cartridge (500 mg of sorbent, aminopropyl) and the cartridges were cleaned with $7.0 \mathrm{ml}$ of 2-propanol and trichloromethane $(1: 2, \mathrm{v} / \mathrm{v})$. The JA and related standard were eluted with $10 \mathrm{ml}$ of diethyl ether and acetic acid $(98: 2, \mathrm{v} / \mathrm{v})$. The residue of solvents after evaporation was esterified with diazomethane and analyzed by GS-MS (6890 N network GC system and the 5973 network mass-selective detector; Agilent Technologies, Palo Alto, CA, USA) in the selected ion mode. The ion fragment was monitored at $\mathrm{m} / \mathrm{z}=83 \mathrm{amu}$, consistent with the base peaks of JA and [9,10-2H2]-9,10-dihydro-JA; the JA was quantified from the peak areas corresponding to the respective standards.

Measurement of lignin content. Lignin content was assessed following a modified version of a previously reported method ${ }^{58}$. Samples weighing $0.6 \mathrm{~g}$ stored at $-80^{\circ} \mathrm{C}$ were ground in liquid nitrogen and washed five times with $95 \%$ ethanol to eliminate soluble metabolites. The homogenate was further washed with acetone and dried in an oven. The dried sample was further disrupted in acetic acid using an ultrasonic machine and centrifuged at $3000 \times g$ for $5 \mathrm{~min}$. The remaining pellet was resuspended in $25 \%$ acetyl bromide and again centrifuged at $3000 \times g$ for $5 \mathrm{~min}$. The samples were mixed with a mixture of acetic acid and acetyl bromide (4:1, $\mathrm{v} / \mathrm{v}$ ) and heated at $70{ }^{\circ} \mathrm{C}$ for $2 \mathrm{~h}$. The samples were cooled at room temperature and transferred to $50 \mathrm{ml}$ of $2 \mathrm{M}$ sodium hydroxide, $1.5 \mathrm{ml}$ of acetic acid, and 7.5 $\mathrm{M}$ hydroxylamine hydrochloride. The volume of each sample was equalized with acetic acid. The supernatant's absorbance was measured with a spectrophotometer at $280 \mathrm{~nm}$ (UV-2450; Shimadzu, Japan).

Statistical analysis. All experiments of each section were performed in triplicate, and the data collected from each replicate were pooled together. The data were analyzed using two-way ANOVA followed by Bonferroni post hoc test (significant difference: $p<0.05$ ). A completely randomized design was used to compare the mean values of different treatments. The data were graphically presented and the statistical analyses were performed using GraphPad Prism software (version 5.01; GraphPad, San Diego, CA, USA).

\section{Conclusion}

This study has provided evidence that the overexpression of OsCM potentially accelerated resistance to BLB stress in rice. The results revealed that the expression of OsCM significantly induced the accumulation of aromatic amino acids, as well as regulation of the PAL pathway and pathways downstream from AAAs. This induction led to the production of specialized metabolites such as lignin, the accumulation of hormones such as SA and JA, and alteration of some specialized amino acids that protect cells from oxidative damage. Here, we found that AAAs such as Phe and Tyr are not only essential for protein synthesis but also serve as precursors of the PAL pathway, which is responsible for the synthesis of a wide range of secondary metabolites. Increased PAL pathway function by the overexpression of $O s C M$ has a positive impact on BLB resistance. Owing to the high accumulation of Phe and up regulation of the genes responsible for the synthesis of Phe compared with that for Tyr in the transgenic line, it was found that Phe is strongly associated with pathogen-related stress compared with Tyr. SA is an essential regulator of plant defense by inducing the expression of defense-related genes. The SA pathway was upregulated while JA was down regulated in infected transgenic plants, which suggested that SA accumulation enhances NPR 1 and $\mathrm{X} a 7$ expression in response to pathogen-related stress. The positive responses of lignin and total amino acid accumulation in response to pathogen-related stress in the OsCM-overexpressing line also indicated that lignin and amino acids are essential parts of plant defense. These results show that AAAs, the PAL pathway, hormones, and pathogen-resistant genes function cooperatively in response to BLB stress in rice.

Received: 16 April 2020; Accepted: 18 October 2020

Published online: 11 November 2020

\section{References}

1. Reddy, A. P. K., MacKenzie, D. R., Rouse, D. I. \& Rao, A. V. Relationship of bacterial leaf blight severity to grain yield of rice. Phytopathology 69, 967-969 (1979).

2. Suh, J. P. et al. Development of breeding lines with three pyramided resistance genes that confer broad-spectrum bacterial blight resistance and their molecular analysis in rice. Rice (New York, N.Y.) 6, 5. https://doi.org/10.1186/1939-8433-6-5 (2013).

3. Tzin, V. \& Galili, G. New insights into the shikimate and aromatic amino acids biosynthesis pathways in plants. Mol. Plant 3, 956-972. https://doi.org/10.1093/mp/ssq048 (2010).

4. Ferrari, S. et al. Resistance to Botrytis cinerea induced in Arabidopsis by elicitors is independent of salicylic acid, ethylene, or jasmonate signaling but requires PHYTOALEXIN DEFICIENT3. Plant Physiol. 144, 367-379. https://doi.org/10.1104/pp.107.09559 6 (2007).

5. Abramovitch, R. B. \& Martin, G. B. Strategies used by bacterial pathogens to suppress plant defenses. Curr. Opin. Plant Biol. 7, 356-364. https://doi.org/10.1016/j.pbi.2004.05.002 (2004).

6. Alfano, J. R. \& Collmer, A. Type III secretion system effector proteins: Double agents in bacterial disease and plant defense. Annu. Rev. Phytopathol. 42, 385-414. https://doi.org/10.1146/annurev.phyto.42.040103.110731 (2004).

7. Truman, W., de Zabala, M. T. \& Grant, M. Type III effectors orchestrate a complex interplay between transcriptional networks to modify basal defence responses during pathogenesis and resistance. Plant J. Cell Mol. Biol. 46, 14-33. https://doi.org/10.1111/j.1365313X.2006.02672.x (2006).

8. Kocal, N., Sonnewald, U. \& Sonnewald, S. Cell wall-bound invertase limits sucrose export and is involved in symptom development and inhibition of photosynthesis during compatible interaction between tomato and Xanthomonas campestris pv vesicatoria. Plant Physiol. 148, 1523-1536. https://doi.org/10.1104/pp.108.127977 (2008).

9. Vogt, T. Phenylpropanoid biosynthesis. Mol. plant 3, 2-20 (2010). 
10. Bartel, B. Auxin biosynthesis. Annu. Rev. Plant Biol. 48, 51-66 (1997).

11. Garcion, C. et al. Characterization and biological function of the ISOCHORISMATE SYNTHASE2 gene of Arabidopsis. Plant Physiol. 147, 1279-1287. https://doi.org/10.1104/pp.108.119420 (2008).

12. Cho, M. H. et al. Phenylalanine biosynthesis in Arabidopsis thaliana. Identification and characterization of arogenate dehydratases. J. Biol. Chem. 282, 30827-30835. https://doi.org/10.1074/jbc.M702662200 (2007).

13. Yamada, T. et al. Mutation of a rice gene encoding a phenylalanine biosynthetic enzyme results in accumulation of phenylalanine and tryptophan. Plant Cell 20, 1316-1329. https://doi.org/10.1105/tpc.107.057455 (2008).

14. Maeda, H. et al. RNAi suppression of AROGENATE DEHYDRATASE1 reveals that phenylalanine is synthesized predominantly via the arogenate pathway in petunia petals. Plant Cell 22, 832-849. https://doi.org/10.1105/tpc.109.073247 (2010).

15. Kaminaga, Y. et al. Plant phenylacetaldehyde synthase is a bifunctional homotetrameric enzyme that catalyzes phenylalanine decarboxylation and oxidation. J. Biol. Chem. 281, 23357-23366. https://doi.org/10.1074/jbc.M602708200 (2006).

16. MacDonald, M. J. \& D’Cunha, G. B. A modern view of phenylalanine ammonia lyase. Biochem. Cell Biol. Biochimie et Biologie Cellulaire 85, 273-282. https://doi.org/10.1139/o07-018 (2007).

17. Anterola, A. M. \& Lewis, N. G. Trends in lignin modification: A comprehensive analysis of the effects of genetic manipulations/ mutations on lignification and vascular integrity. Phytochemistry 61, 221-294. https://doi.org/10.1016/s0031-9422(02)00211-x (2002).

18. Nair, R. B., Bastress, K. L., Ruegger, M. O., Denault, J. W. \& Chapple, C. The Arabidopsis thaliana REDUCED EPIDERMAL FLUORESCENCE1 gene encodes an aldehyde dehydrogenase involved in ferulic acid and sinapic acid biosynthesis. Plant Cell 16, 544-554. https://doi.org/10.1105/tpc.017509 (2004).

19. Somegowda, M., Vigneshwaran, V., Rajeshwar, A. N., Shivashankar, S. \& Pramod, S. N. Biotic stress induced by Bacterocera cucurbitae (Melon Fly) triggers defense related phenylpropanoid pathway (PPP) and ROS detoxifying enzymes in cucurbits as adaptation. Asian J. Plant Sci. Res. 7, 18-29 (2017).

20. Le Thanh, T. et al. Salicylic acid-induced accumulation of biochemical components associated with resistance against Xanthomonas oryzae pv. oryzae in rice. J. Plant Interact. 12, 108-120. https://doi.org/10.1080/17429145.2017.1291859 (2017).

21. Wang, D., Amornsiripanitch, N. \& Dong, X. A genomic approach to identify regulatory nodes in the transcriptional network of systemic acquired resistance in plants. PLoS Pathog. 2, e123. https://doi.org/10.1371/journal.ppat.0020123 (2006).

22. Withers, J. \& Dong, X. Posttranslational modifications of NPR1: A single protein playing multiple roles in plant immunity and physiology. PLoS Pathog. 12, e1005707. https://doi.org/10.1371/journal.ppat.1005707 (2016).

23. Verma, V., Ravindran, P. \& Kumar, P. P. Plant hormone-mediated regulation of stress responses. BMC Plant Biol. 16, 86. https:// doi.org/10.1186/s12870-016-0771-y (2016).

24. Spoel, S. H. et al. NPR1 modulates cross-talk between salicylate- and jasmonate-dependent defense pathways through a novel function in the cytosol. Plant Cell 15, 760-770. https://doi.org/10.1105/tpc.009159 (2003).

25. Friedrich, L. et al. NIM1 overexpression in Arabidopsis potentiates plant disease resistance and results in enhanced effectiveness of fungicides. Mol. Plant Microbe Interact. 14, 1114-1124 (2001).

26. Das, B., Sengupta, S., Prasad, M. \& Ghose, T. K. Genetic diversity of the conserved motifs of six bacterial leaf blight resistance genes in a set of rice landraces. BMC Genet. 15, 82 (2014).

27. Moura, J. C., Bonine, C. A., de Oliveira Fernandes Viana, J., Dornelas, M. C. \& Mazzafera, P. Abiotic and biotic stresses and changes in the lignin content and composition in plants. J Integr Plant Biol 52, 360-376. https://doi.org/10.1111/j.1744-7909.2010.00892 .x (2010).

28. Alcazar, R. et al. Involvement of polyamines in plant response to abiotic stress. Biotech. Lett. 28, 1867-1876. https://doi.org/10.1007/ s10529-006-9179-3 (2006).

29. Jones, J. D. G. \& Dangl, J. L. The plant immune system. Nature 444, 323-329. https://doi.org/10.1038/nature05286 (2006).

30. Payyavula, R. S., Navarre, D. A., Kuhl, J. C., Pantoja, A. \& Pillai, S. S. Differential effects of environment on potato phenylpropanoid and carotenoid expression. BMC Plant Biol. 12, 39. https://doi.org/10.1186/1471-2229-12-39 (2012).

31. Dixon, R. A. \& Paiva, N. L. Stress-induced phenylpropanoid metabolism. Plant Cell 7, 1085-1097. https://doi.org/10.1105/ tpc.7.7.1085 (1995).

32. La Camera, S. et al. Metabolic reprogramming in plant innate immunity: the contributions of phenylpropanoid and oxylipin pathways. Immunol. Rev. 198, 267-284. https://doi.org/10.1111/j.0105-2896.2004.0129.x (2004).

33. Rippert, P. \& Matringe, M. Purification and kinetic analysis of the two recombinant arogenate dehydrogenase isoforms of Arabidopsis thaliana. Eur. J. Biochem. 269, 4753-4761. https://doi.org/10.1046/j.1432-1033.2002.03172.x (2002).

34. Manela, N. et al. Phenylalanine and tyrosine levels are rate-limiting factors in production of health promoting metabolites in Vitis vinifera cv. Gamay Red cell suspension. Front. Plant Sci. 6, 538. https://doi.org/10.3389/fpls.2015.00538 (2015).

35. Oliva, M. et al. Enhanced formation of aromatic amino acids increases fragrance without affecting flower longevity or pigmentation in Petunia x hybrida. Plant Biotechnol J 13, 125-136. https://doi.org/10.1111/pbi.12253 (2015).

36. Kachroo, A. \& Kachroo, P. Fatty acid-derived signals in plant defense. Annu. Rev. Phytopathol. 47, 153-176. https://doi.org/10.1146/ annurev-phyto-080508-081820 (2009).

37. Yan, X. \& Chen, S. Regulation of plant glucosinolate metabolism. Planta 226, 1343-1352. https://doi.org/10.1007/s00425-0070627-7 (2007).

38. Shine, M. B. et al. Cooperative functioning between phenylalanine ammonia lyase and isochorismate synthase activities contributes to salicylic acid biosynthesis in soybean. New Phytol. 212, 627-636. https://doi.org/10.1111/nph.14078 (2016).

39. Catinot, J., Buchala, A., Abou-Mansour, E. \& Metraux, J. P. Salicylic acid production in response to biotic and abiotic stress depends on isochorismate in Nicotiana benthamiana. FEBS Lett. 582, 473-478. https://doi.org/10.1016/j.febslet.2007.12.039 (2008).

40. Pallas, J. A., Paiva, N. L., Lamb, C. \& Dixon, R. A. Tobacco plants epigenetically suppressed in phenylalanine ammonia-lyase expression do not develop systemic acquired resistance in response to infection by tobacco mosaic virus. Plant J. 10, 281-293. https://doi.org/10.1046/j.1365-313X.1996.10020281.x (1996).

41. Yoo, H. et al. An alternative pathway contributes to phenylalanine biosynthesis in plants via a cytosolic tyrosine:phenylpyruvate aminotransferase. Nat. Commun. 4, 2833. https://doi.org/10.1038/ncomms3833 (2013).

42. Less, H. \& Galili, G. Principal transcriptional programs regulating plant amino acid metabolism in response to abiotic stresses. Plant Physiol. 147, 316-330. https://doi.org/10.1104/pp.108.115733 (2008).

43. Subramanian, S., Graham, M. Y., Yu, O. \& Graham, T. L. RNA interference of soybean isoflavone synthase genes leads to silencing in tissues distal to the transformation site and to enhanced susceptibility to Phytophthora sojae. Plant Physiol. 137, 1345-1353. https://doi.org/10.1104/pp.104.057257 (2005).

44. Zabala, G. et al. Transcriptome changes in the phenylpropanoid pathway of Glycine max in response to Pseudomonas syringae infection. BMC Plant Biol. 6, 26. https://doi.org/10.1186/1471-2229-6-26 (2006).

45. Graham, T. L., Graham, M. Y., Subramanian, S. \& Yu, O. RNAi silencing of genes for elicitation or biosynthesis of 5-deoxyisoflavonoids suppresses race-specific resistance and hypersensitive cell death in Phytophthora sojae infected tissues. Plant Physiol. 144, 728-740. https://doi.org/10.1104/pp.107.097865 (2007).

46. Bari, R. \& Jones, J. D. Role of plant hormones in plant defence responses. Plant Mol. Biol. 69, 473-488. https://doi.org/10.1007/ s11103-008-9435-0 (2009).

47. Robert-Seilaniantz, A., Navarro, L., Bari, R. \& Jones, J. D. Pathological hormone imbalances. Curr. Opin. Plant Biol. 10, 372-379. https://doi.org/10.1016/j.pbi.2007.06.003 (2007). 
48. Cui, J. et al. Pseudomonas syringae manipulates systemic plant defenses against pathogens and herbivores. Proc. Natl. Acad. Sci. USA 102, 1791-1796. https://doi.org/10.1073/pnas.0409450102 (2005).

49. Laurie-Berry, N., Joardar, V., Street, I. H. \& Kunkel, B. N. The Arabidopsis thaliana JASMONATE INSENSITIVE 1 gene is required for suppression of salicylic acid-dependent defenses during infection by Pseudomonas syringae. Mol. Plant-Microbe Interact. MPMI 19, 789-800. https://doi.org/10.1094/mpmi-19-0789 (2006).

50. Kempema, L. A., Cui, X., Holzer, F. M. \& Walling, L. L. Arabidopsis transcriptome changes in response to phloem-feeding silverleaf whitefly nymphs. Similarities and distinctions in responses to aphids. Plant Physiol. 143, 849-865. https://doi.org/10.1104/ pp.106.090662 (2007).

51. Adie, B. A. et al. ABA is an essential signal for plant resistance to pathogens affecting JA biosynthesis and the activation of defenses in Arabidopsis. Plant Cell 19, 1665-1681. https://doi.org/10.1105/tpc.106.048041 (2007).

52. Dong, X. NPR1, all things considered. Curr. Opin. Plant Biol. 7, 547-552. https://doi.org/10.1016/j.pbi.2004.07.005 (2004).

53. Webb, K. M. et al. A benefit of high temperature: Increased effectiveness of a rice bacterial blight disease resistance gene. New Phytol. 185, 568-576. https://doi.org/10.1111/j.1469-8137.2009.03076.x (2010).

54. Hopkins, C. M., White, F. F., Choi, S. H., Guo, A. \& Leach, J. E. (1992) Identification of a family of avirulence genes from Xanthomonas oryzae pv. oryzae. Mol. Plant-Microbe Interact. MPMI 5, 451-459. https://doi.org/10.1094/mpmi-5-451 (1992).

55. Cohen, S. P. et al. RNA-Seq analysis reveals insight into enhanced rice Xa7-mediated bacterial blight resistance at high temperature. PLoS ONE 12, e0187625. https://doi.org/10.1371/journal.pone.0187625 (2017).

56. Spoel, S. H., Johnson, J. S. \& Dong, X. Regulation of tradeoffs between plant defenses against pathogens with different lifestyles. Proc. Natl. Acad. Sci. USA 104, 18842-18847. https://doi.org/10.1073/pnas.0708139104 (2007).

57. Durner, J. \& Klessig, D. F. Inhibition of ascorbate peroxidase by salicylic acid and 2,6-dichloroisonicotinic acid, two inducers of plant defense responses. Proc. Natl. Acad. Sci. USA 92, 11312-11316. https://doi.org/10.1073/pnas.92.24.11312 (1995).

58. Zheng, M. et al. Manipulation of lignin metabolism by plant densities and its relationship with lodging resistance in wheat. Sci. Rep. 7, 41805. https://doi.org/10.1038/srep41805 (2017).

59. Mauch-Mani, B. \& Slusarenko, A. J. Production of salicylic acid precursors is a major function of phenylalanine ammonia-lyase in the resistance of arabidopsis to Peronospora parasitica. Plant Cell 8, 203-212. https://doi.org/10.1105/tpc.8.2.203 (1996).

60. Cass, C. L. et al. Effects of PHENYLALANINE AMMONIA LYASE (PAL) knockdown on cell wall composition, biomass digestibility, and biotic and abiotic stress responses in Brachypodium. J. Exp. Bot. 66, 4317-4335. https://doi.org/10.1093/jxb/erv269 (2015).

61. Vanholme, R. et al. A systems biology view of responses to lignin biosynthesis perturbations in Arabidopsis. Plant Cell 24, 35063529. https://doi.org/10.1105/tpc.112.102574 (2012).

62. Hildebrandt, T. M., Nesi, A. N., Araújo, W. L. \& Braun, H.-P. Amino acid catabolism in plants. Mol. Plant 8, 1563-1579. https:// doi.org/10.1016/j.molp.2015.09.005 (2015).

63. Pratelli, R. \& Pilot, G. Regulation of amino acid metabolic enzymes and transporters in plants. J. Exp. Bot. 65, 5535-5556. https:// doi.org/10.1093/jxb/eru320 (2014)

64. Chen, H., Wang, S. \& Zhang, Q. New gene for bacterial blight resistance in rice located on chromosome 12 identified from minghui 63, an elite restorer line. Phytopathology 92, 750-754. https://doi.org/10.1094/phyto.2002.92.7.750 (2002).

65. Hao, P. et al. Roles of NlAKTIP in the growth and eclosion of the rice brown planthopper, Nilaparvata lugens Stål, as revealed by RNA interference. Int. J. Mol. Sci. 16, 22888-22903. https://doi.org/10.3390/ijms160922888 (2015).

66. Xu, C., Xu, Y. \& Huang, B. Protein extraction for two-dimensional gel electrophoresis of proteomic profiling in turfgrass. Crop Sci. 48, 1608-1614 (2008).

67. Jan, R., Khan, M. A., Asaf, S., Lee, I.-J. \& Kim, K. M. Metal resistant endophytic bacteria reduces cadmium, nickel toxicity, and enhances expression of metal stress related genes with improved growth of Oryza sativa, via regulating its antioxidant machinery and endogenous hormones. Plants 8, 363 (2019).

68. Khan, M. A. et al. Gibberellin application ameliorates the adverse impact of short-term flooding on Glycine max L. Biochem. J. https://doi.org/10.1042/bcj20180534 (2018).

69. McCloud, E. S. \& Baldwin, I. T. Herbivory and caterpillar regurgitants amplify the wound-induced increases in jasmonic acid but not nicotine in Nicotiana sylvestris. Planta 203, 430-435. https://doi.org/10.1007/s004250050210 (1997).

\section{Acknowledgements}

This work was supported by a Grant from the New breeding technologies development Program (Project No. PJ014793012020), Rural Development Administration, Republic of Korea.

\section{Author contributions}

R.J. made contributions as first author. R.J., J.S.B, K.M.K., and I.J.L. designed the study; R.J. performed experiments; M.A.K. and S.A. performed analyses; and R.J., J.S.B. and K.M.K. performed experiments and wrote the manuscript.

\section{Competing interests}

The authors declare no competing interests.

\section{Additional information}

Supplementary information is available for this paper at https://doi.org/10.1038/s41598-020-76675-1.

Correspondence and requests for materials should be addressed to J.-S.B. or K.-M.K.

Reprints and permissions information is available at www.nature.com/reprints.

Publisher's note Springer Nature remains neutral with regard to jurisdictional claims in published maps and institutional affiliations. 
(c) (i) Open Access This article is licensed under a Creative Commons Attribution 4.0 International cc) License, which permits use, sharing, adaptation, distribution and reproduction in any medium or format, as long as you give appropriate credit to the original author(s) and the source, provide a link to the Creative Commons licence, and indicate if changes were made. The images or other third party material in this article are included in the article's Creative Commons licence, unless indicated otherwise in a credit line to the material. If material is not included in the article's Creative Commons licence and your intended use is not permitted by statutory regulation or exceeds the permitted use, you will need to obtain permission directly from the copyright holder. To view a copy of this licence, visit http://creativecommons.org/licenses/by/4.0/.

(C) The Author(s) 2020 